\title{
Book Review: Case Studies in Forensic Anthropology:
}

\section{Bonified Skeletons}

\section{By Heather M. Garvin and Natalie R. Langley, CRC Press Reviewed by Samantha Coberly, University of Florida}

Case Studies in Forensic Anthropology: Bonified Skeletons, edited by Drs. Heather M. Garvin and Natalie R. Langley features case studies by forensic anthropologists from all across the globe. The book includes chapters from established scholars in the field as well as up and coming practitioners. The book is split into five sections: Estimation of Biological Profile and Positive Identification; Forensic Taphonomy; Trauma; Human Rights and Mass Disasters; and Other Considerations. Some of the sections are more diverse in their topics than others. The taphonomy section in particular has an assorted array of topics, with chapters on thermal damage, chemical damage, dismemberments, water depositions and mites. Estimation of the biological profile on the other hand is narrower in scope as it mainly focuses on ancestry, although the identification portion of that section has several different types of identification presented. There are 4-6 chapters in each section for a total of 27 chapters. The chapters are not long, ranging from 7-16 pages for a total of roughly 300 pages. Each chapter presents one or more case studies that illustrate a specific topic. All the chapters met the goal of presenting a clear concise case study that dealt with the history of the case, the analyses of interest and the outcome if known.

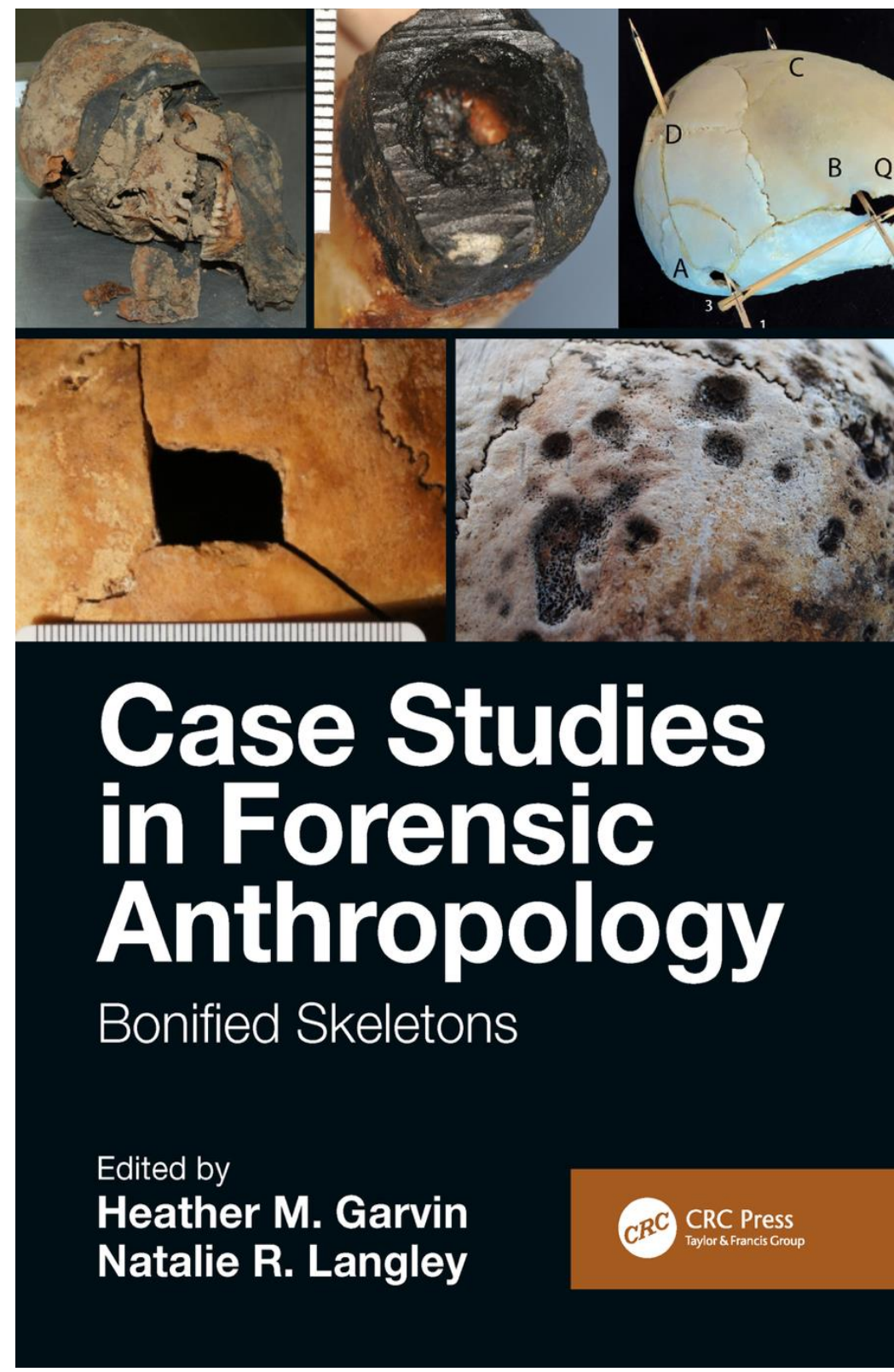

The book is well organized and with some standardization. Each chapter has a lesson learned section and a set of discussion questions. It is interesting to see how each author interpreted these parts of the chapter. Some authors choose discussion questions that were more specific to the case presented in the chapter while others proposed more overarching questions about the topic and the 
field. There were some differences in how each author approached their chapter. A few authors gave a more bare-bones description of the case with little background on the topic the case is showcasing. Others gave a more detailed background on the topic citing multiple studies. There were a few chapters that left me wishing the authors had gone into the background more extensively. Several of the cases presented were unresolved according to the chapter(s): the perpetrator may not have been caught; there was no next of kin for DNA; the forensic anthropologist was not told the outcome of the trial. All of these endings, while not satisfactory to the reader, do well to show the reality of investigations.

According to the editors, the book is intended for both upper level students of anthropology as well as those already practicing within the field. I would say the lessons learned and discussion questions are more geared to the student audience rather than the professional one. The student should already have an understanding of the basics of forensic anthropology and osteology. Many of the questions were ones that would be asked in a classroom setting for students still learning about forensic methodology. Students would also benefit from seeing the methods they are learning about implemented in a real-life scenario. Perhaps a further study section would have been beneficial to students as well, for when they want to explore a topic further. There were a few chapters that proposed questions which professionals should also be considering in terms of how the field approaches certain topics such as how anthropologists determine ancestry and how ancestry is reported to medical examiners and law enforcement. The book does have up to date methodologies and techniques that professionals should be aware of. An example of this is chapter one which discusses the use of social media in homicide investigations. For both the student and the professional the book does have some very interesting case studies that do a satisfactory job of highlighting the methods and techniques the authors wished to discuss.

The editors also note that one of the book's key features are the color photos; they really are stunning. All photos included add value to the topic and clearly illustrate the important points or concepts the authors are making in the chapter. Even chapters without color photos have well defined figures that do well to showcase the author's points. Another key feature is the thought process of each individual examining the cases. Each author discusses the analyses that led them to their conclusions such as what methods they used to generate a biological profile or their trauma assessment. One of the strengths of the book was the detailing of the thought process and rationale behind each of the decisions the forensic anthropologists made which would be helpful for both students and professionals.

Overall, the book would be a good one to have in any forensic anthropologist's collection whether they are students or professionals. The photos are great and the cases interesting. The book has thorough information about up to date methods and techniques and their application in the field of forensic anthropology today. 